\title{
Induction of the Mice Model Regarding the Endometriosis and Assessment of Antioxidant Treatment Effectiveness: An Experimental Protocol
}

\author{
Hayedeh Hoorsan $^{1}{ }^{\circledR}$, Masoumeh Simbar $^{2^{*}}$, Fahimeh Ramezani Tehrani ${ }^{(\mathbb{D}}$, Fardin Fathi $^{\circledR}{ }^{\mathbb{D}}$, Nariman \\ Mosaffa $^{(\mathbb{D}}$, Hedyeh Riazi $^{(\mathbb{D}}$
}

\begin{abstract}
Objectives: Over the past twenty years, the role of inflammatory, immunologic, and stress oxidative factors in the pathogenesis of endometriosis has been emphasized in the literature. Endometrial induced lesions in the surgical endometriosis model of mice are similar to those observed in women. Therefore, the present study evaluated the effects of vitamin $\mathrm{C}$ treatment on the endometriosis mice model. More precisely, it aimed to induce an optimum model of endometriosis using both peritoneal and ovarian approaches and to compare the histological and fertility changes in the first-generation infants of endometriosis induced, sham, and control groups. Finally, the study assessed the influence of vitamin $\mathrm{C}$ administration treatment on the induced endometriosis mice model and its first-generation infants.

Methods: This experimental study was done in three phases. In the first phase, 32 mice were randomly divided into four groups receiving induced endometriosis through peritoneal approach, induced endometriosis through an ovarian approach, as well as sham and control groups. The histological and fertility characteristics of the first generation of ovarian endometriosis, sham, and control groups were compared in the second phase. Then, the histological and fertility characteristics of those endometriosis induced models receiving vitamin $\mathrm{C}$ were compared with the controls, and the first generation of these groups was compared as well.

Results: This experimental study began in April 2017 and will be finished in 2020.

Conclusions: The results of this study improve our knowledge about the mechanisms involved in endometriosis progressions. The results further provide a comprehensive animal model for further research and assess the therapeutic role of antioxidants.

Keywords: Model of endometriosis, Mice, First-generation, Antioxidant treatment
\end{abstract}

\section{Introduction}

Endometriosis is a chronic hormone-inflammatory disease with known symptoms such as infertility and pelvic pains. It influences the health of the women in their reproductive span, and is characterized by stroma outside the uterus and endometrial glands, physically, psychologically, and socially (1-3).

The prevalence of this disease is about $10 \%$ and it is reported between $20-90 \%$ for women with infertility or pelvic pain $(4,5)$. Three theories were suggested to explain the pathogenesis of endometriosis, including endometrial tissue ectopic transplantation, coelomic metaplasia, and the induction theories. Although retrograde occurs in $90 \%$ of women, the disease develops only in some of them. Therefore, various mechanisms such as epigenetic and inflammatory factors, immune disorders, as well as hormones, and environmental factors may contribute to the onset of endometriosis, establishment, progression/ backwardness, symptoms, signs, and the complications of this disease (4,6-10). Oxidative stress has a potential role in the inflammatory process, cell proliferation, and the apoptosis prevention of the endometriotic cell growth of endometrial lesions $(11,12)$.

Due to ethical constraints in the trial studies of infertility in women with endometriosis, animal models are valuable tools for controlling the risk factors, outbreak, and pathogenesis of endometriosis (13). The induction models of endometriosis are very diverse, for instance, the induction of peritoneal, ovarian, and subcutaneous, in the forms of autotransplant or hetrotransplant. The ovarian is considered as the most common site for endometriosis while most studies have examined the peritoneal endometriosis induction (14).

This study aims to extract an optimum model using in

${ }^{1}$ Student Research Committee, School of Nursing and Midwifery, Shahid Beheshti University of Medical Sciences, Tehran, Iran. ${ }^{2}$ Department of Midwifery and Reproductive Health, School of Nursing and Midwifery, Reproductive Endocrinology Research Center, Research Institute for Endocrine Sciences, Shahid Beheshti University of Medical Science, Tehran, Iran. ${ }^{3}$ Reproductive Endocrinology Research Center, Research Institute for Endocrine Sciences, Shahid Beheshti University of Medical Sciences, Tehran, Iran. ${ }^{4}$ Cellular and Molecular Research Center, Research Institute for Health Development, Kurdistan University of Medical Sciences, Sanandaj, Iran. ${ }^{5}$ Department of Immunology, School of Medicine, Shahid Beheshti University of Medical Sciences, Tehran, Iran. ${ }^{6}$ Department of Midwifery and Reproductive Health, School of Nursing and Midwifery, Shahid Beheshti University of Medical Sciences, Tehran, Iran.

*Corresponding Author: Masoumeh Simbar, Tel: +9821 88655376; Email: msimbar@sbmu.ac.ir, msimbar@gmail.com 
later stages of the research according to histological and fertility changes and investigates the influences of vitamin $\mathrm{C}$ administration on the treatment of endometriosis in terms of size, adhesion formation and angiogenic in addition to inflammatory and stress oxidative gene expression levels, followed by re-assessing these inductions and therapeutic effects in the next generation.

\section{Methods/Design}

This experimental study was conducted in 3 phases in April 2017. Ninety-five virgin female NMRI mice (25$35 \mathrm{~g}, 6-8$ weeks) were obtained from the central animal unit of Kurdistan Medical Sciences University and used for this study. All animals were performed following the Animals (Scientific Procedures) Act 1986 Amendment Regulations 2012 (15). The checklist of working with laboratory animals was completed based on the guidelines for working with the laboratory animals of the Ministry of Health, and Medical Education of Iran and was submitted along with the proposal.

Mice were housed in cages (3 per cage) in a wellventilated room under standard 12-12-hour light-dark cycles with the temperature range of $22-25^{\circ} \mathrm{C}$ and the humidity of 55\%-60\%. In addition, mice had ad libitum access to food and water and were maintained under standard conditions for one week in order to observe their health conditions before the experiment while the conditions were maintained the same during the study. Body weights were measured and recorded every week throughout the experimental period.

The estrous cycle was identified by observing vaginal smears at 8-10 AM and then the smears were fixed with alcohol 70\%, stained with Giemsa, and finally, examined by a light microscope $(\times 100$ magnification). The proportion of leukocytes, along with epithelial and cornified cells was found in the vaginal smear, which characteristically changed during different stages of the estrous cycle thus the estrous cycles (estrus, diestrus 1 [metestrus], diestrus 2 , and proestrus) were recognized. All procedures, including surgery, endometriosis induction, and tissue collection were performed in the estrous phase.

\section{Study Phases}

\section{A. Induction of Endometriosis Model}

At this phase, thirty-two 6-8-week mice from the animal laboratory of Kurdistan University of Medical Sciences were prepared and allowed to take a new environment for at least 1 week.

Thirty-two mice were randomly divided into 4 groups. The endometriosis was induced surgically in 2 groups using peritoneal ( 8 mice) and ovarian ( 8 mice) approaches. Further, the third group was sham (8 mice) underwent a surgical procedure while the fourth group was considered as control (8 mice) and received no surgery.

1. All surgical procedures were performed at the estrous phase which was identified by the observation of vaginal smears, and after 4 weeks, the mice were sacrificed using the isoflurane.

2. The clinical adhesion and the size of implants were evaluated and photographed as well.

3. Tissue samples were collected for histological, immunological, and cellular assessment.

Figure 1 illustrates an overview of the first phase protocol.

B. Comparison of Histological and Fertility Characteristics of First-Generation Infants Among Endometriosis Induction, Sham, and Control Groups

The histological and fertility features of first-generation infants of 3 study groups, including the optimum selected model, sham, and control groups, were compared in this phase. The following steps were considered for this phase.

1. Twenty-one female mice were randomly divided into endometriosis, sham, and control groups.

2. Endometriosis and sham groups were induced surgically.

3. The second look laparotomy was carried out 4 weeks later.

4. One week after the second surgery, each mouse of the 3 groups was placed into a cage with one proven breeder male on the evening of the first estrus.

5. The next morning, if the vaginal plague was observed, it was considered as the first day of gestation.

6. If the mice were not fertilized after 3 times, it was labeled as infertility.

7. In each group, the pregnant mice delivered and then the number of alive and dead newborns was recorded as well.

8. Fourteen female pups from each group were allowed to maturate sexually.

9. Seven subsequent generation mice from each group were sacrificed with isoflurane asphyxiation.

10. Uterine and ovary tissues were collected for histological, immunological, and cellular examination.

11. Seven subsequent generation mature females from each group were bred to the proven breeder males. On the 15th day of pregnancy, they were sacrificed with isoflurane asphyxiation, followed by counting and the numbers of implantation sites and fetuses. Figure 2 displays an overview of the second phase protocol.

\section{Effectiveness of Antioxidant Treatment}

The effect of antioxidant therapy on ovarian induction and the first generation was studied at this phase.

1. In general, 42 mice were induced by ovarian endometriosis in the estrus phase.

2. In the second laparotomy (after 4 weeks), the clinical adhesion and size of the implants were evaluated and photographed after the collection of the peritoneal fluid.

3. After 3 days, 42 mice were randomly segmented into 


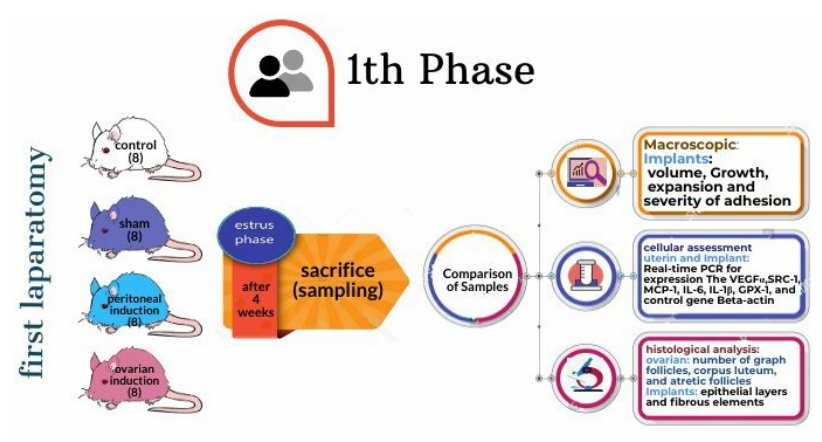

Figure 1. The First Phase of the Study.

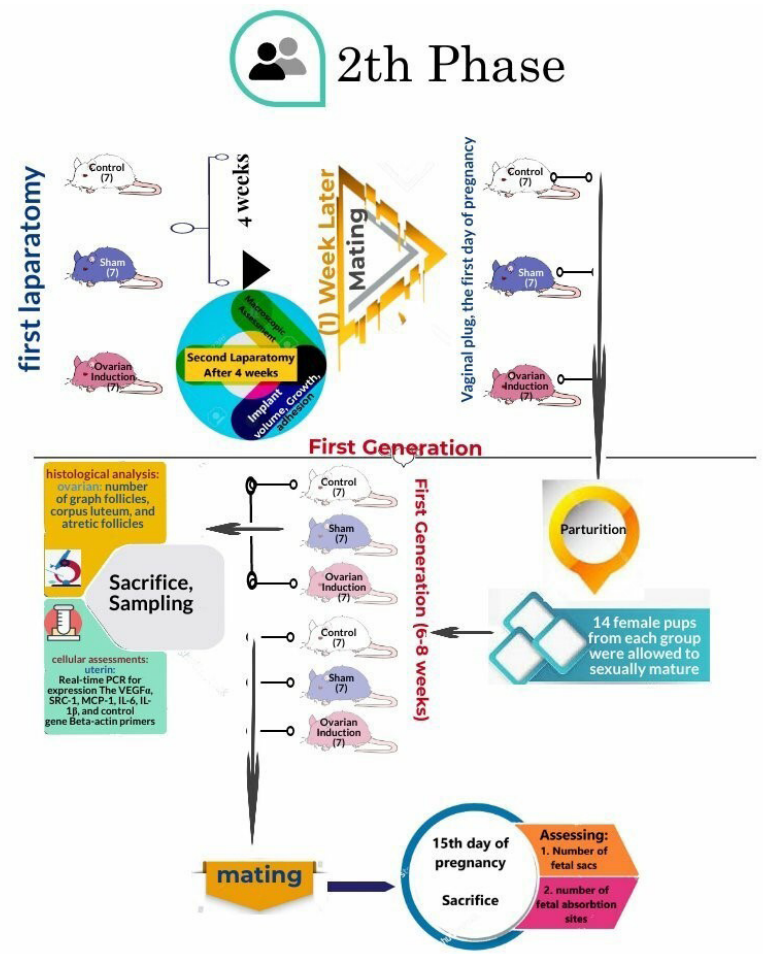

Figure 2. The Second Phase of the Study.

treatment and control groups.

4. The treatment group was given $50 \mathrm{mg} / \mathrm{kg}(0.5 \mathrm{~mL})$ vitamin C (500 mg Nature Made, American, Health Code Certificate 310009077035) every 2 days orally for 4 weeks. Furthermore, the control group was administered $0.5 \mathrm{~mL}$ mix of water and starch. The researcher was blinded to the groups.

4.1. To administer the medicine, the equivalent human dose should be calculated for the animal and the animal equivalent dose (AED) was calculated as

4.2. $\operatorname{AED}(\mathrm{mg} / \mathrm{kg})=$ Human dose $(\mathrm{mg} / \mathrm{kg}) \times \mathrm{Km}$ ratio

4.3. $\mathrm{Km}$ ratio for mice $=12.3$, human dose $=2 \mathrm{mg} / \mathrm{kg}$ $(120 \mathrm{mg} / \mathrm{d})$

4.4. $\mathrm{AED}=24.6 / \mathrm{kg} / \mathrm{dIs}$ almost equal to $50 \mathrm{mg} / \mathrm{kg}$ every 2 days $(16,17)$.
4.5. The drugs were delivered to the researcher in the same containers as $\mathrm{A}$ and $\mathrm{B}$, and the researcher was blind to prescription drugs.

5. Seven mice from each group were sacrificed (the disinfection of the skin of each mouse with a mix of povidone-iodine $10 \%$ and ethanol $70 \%$ ) and peritoneal fluids were collected after 4 weeks (performing peritoneal lavage with $2 \mathrm{~mL}$ of saline).

6. The macroscopic score was determined after observing the implants.

7. The remaining mouse of each 2 groups was placed into a cage with one proven breeder male.

8. If the mice were not fertilized after 3 times, it was labeled as infertility.

9. On the 15th day of pregnancy, 7 mice from each group were sacrificed with isoflurane asphyxiation, followed by counting the numbers of viable, nonviable fetal sacs, and spontaneous fetal absorption sites.

10. The effect of treatment on the next generation was investigated according to stages 7-11 of the second phase of the study.

An overview of the third phase protocol is depicted in Figure 3.

Data Collection Methods

Macroscopic Assessment: Endometriotic implants (the size,

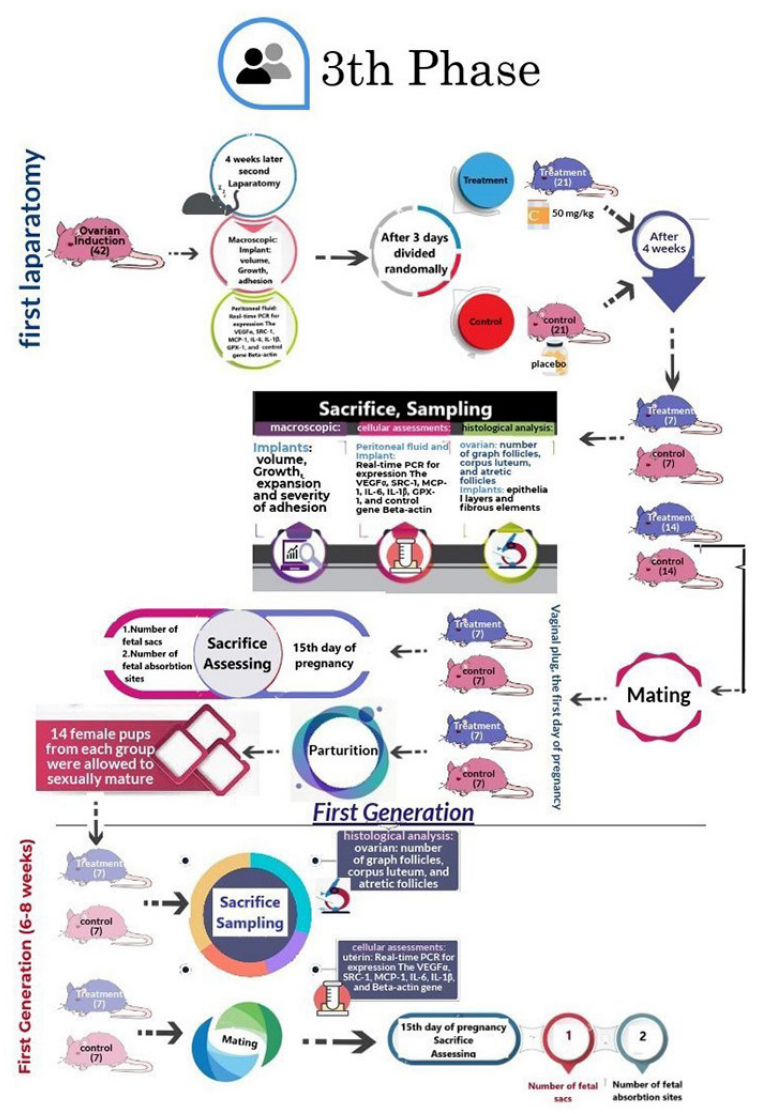

Figure 3. The Third Phase of the Study. 
volume, and weight of endometriotic implants, growth score, and adhesion score);

Histology Assessment: The ovarian tissue (the number of antral follicles, corpus luteum, and atretic follicles) and endometriotic lesion (histologic and trichrome fibrosis scores);

Gene Expression Analysis: The endometriotic lesion tissue, the uterine tissue, and the peritoneal fluid (the gene expression of VEGFa, SRC-1, MCP-1, GPx-1, IL-6, IL-1 $\beta$, and endogenous control beta-actin).

\section{Induction of Endometriosis}

The surgical induction of endometriosis in mice was achieved through autologous transplantation. The mice in the estrus underwent endometriosis surgically with aseptic techniques as follows.

1. The weight of the mice was recorded for anesthetic dose calculation.

2. Vitamin A ointment was used to prevent ocular dryness during the operation.

3. A heater was placed on the surgical table to protect from hypothermia.

4. The mice were anesthetized with intraperitoneal injections of $50 \mathrm{mg} / \mathrm{kg}$ ketamine plus $7 \mathrm{mg} / \mathrm{kg}$ xylazine.

5. Each mouse was placed on the surgical board in the supine (for peritoneal induction) and prone position (for ovarian induction) while abducting the limbs.

6. The location of the operation was shaved and prepared with 3 swabs of scrubs impregnated with betadine and $70 \%$ ethanol.

7. In peritoneal endometriosis cases:

a. The uterus was exposed by a small abdominal incision (approximately $1.5-2 \mathrm{~cm}$ ).

b. The ligation of the left uterine horn was done using 5.0 vicryl sutures (Ethicon, Denmark) at both uterotubal and cervicouterine junctions and then removed to a sterile petri dish container warm phosphate-buffered saline (containing 100 $\mathrm{IU} / \mathrm{mL}$ penicillin and $100 \mu \mathrm{g} / \mathrm{mL}$ streptomycin). Moreover, 0.5-1 mL phosphate-buffered saline was poured into the abdominal cavity to prevent drying and adhesion.

c. The uterine horn was splitted longitudinally while the forceps were held with the blade of corneal scissors. Using a $3 \mathrm{~mm}$ punch biopsy (Sklar, TruUnch, India), the tissue was divided into three 3 $\times 3 \mathrm{~mm}$ sections.

d. The mesentery of the small intestine was spread over a wet gauze so that blood vessels were visible. The implants were sutured around the blood vessels in the mesenteric area using 6-O silk sutures (Ethicon, Denmark).

8. The back area was entered through the left-back area, lower than the spine, and underneath the kidney, the uterus was exteriorized, and the left side of the uterine horn was ligated and dissected in ovarian endometriosis.

a. Then, the uterine horn was cut into 2 pieces $(3 \times 3$ $\mathrm{mm}$ ) longitudinally.

b. The pieces of the uterine horn were implanted on the ovary using 6-0 black silk and blue nylon sutures.

9. The suture of the implant was pulled slowly and carefully so that not to tear the peritoneum and ovary.

10. The duration of endometriosis surgery for each mouse was limited to 20 minutes.

11. All organs (i.e., the intestines, the ovary, and the remaining uterine horns) were replaced in the abdominal cavity.

12. Eventually, 5-0 separate vicryl sutures were used to close the abdominal wall and the skin was closed with nylon 5.0 sutures.

\section{Surgery in the Sham Group}

The steps of the operation in the sham group were similar to those of endometriosis surgery but without the transplantation of tissue masses.

\section{Animal Recovery}

1. Buprenorphine was administrated at a dose of 0.2 $\mathrm{mg} / \mathrm{kg}$ after the surgery to relieve pain.

2. The animal was put into the ventral side down and under the heat lamp to maintain its body temperature. Usually, the mice were completely normal up to 12-24 hours after the operation.

3. The mice were observed every 15 minutes then hourly until they regained their normal activity after the surgery.

4. The mice were individually caged after the operation for a recovery period.

\section{Second-Look Laparotomy}

Four weeks after endometriosis induction, a second-look laparotomy was performed, followed by considering the following steps.

1. All stages of environment and animal preparation were executed according to the first surgical procedure.

2. In the estrus phase, each mouse was anesthetized and a midventral laparotomy or left lower back incision was performed for peritoneal or ovarian ENDO, respectively.

3. Before the second surgery, the peritoneal fluid was collected and then immediately frozen in the liquid nitrogen and stored at $-80{ }^{\circ} \mathrm{C}$ of the freezer until the assay.

4. The maximum diameter of each site of the explants was measured to the nearest tenth of a $\mathrm{mm}$ with a Vernier caliper. 
5. The spherical volume of the implants was calculated as well.

6. The adhesion severity was obtained as follows.

$0=$ Without resisting to separation

$0.5=$ Partially resistant to separation

$1=$ Sharp dissection

7. The extent of adhesion was obtained as:

$0=$ No adhesions points

$1=$ Points $25 \%$ of traumatized area

$2=$ Points $50.0 \%$ of traumatized area

$3=$ The whole points of traumatized area involvement

8. The growth of the implant was scored as follows (18).

$1=$ The implant vanished or it was visible without the vesicle;

$2=$ The implant fashioned a vesicle with the major dimension less than $2 \mathrm{~mm}$;

3 = The implant fashioned a cyst containing fluid, with the major dimension $\geq 2 \mathrm{~mm}$, but $<4.5 \mathrm{~mm}$;

$4=$ The major dimension of the vesicle was $\geq 4.5$, but $<6$;

5 = Implant size $\geq 6 \mathrm{~mm}$.

9. The abdominal incision was closed at the end of the surgery, followed by performing the recovery steps.

Sacrificing the Animal

1. The mice were weighed.

2. In the estrus stage, the mice were sacrificed by isoflurane asphyxiation and were dissected.

3. The endometriosis lesions were evaluated and scored based on macroscopic findings.

4. Endometriotic implants were excised and weighed accurately.

5. One of the ovaries, one of the implants, the peritoneal fluid, and half of the remaining uterus were transferred to the RNase DNase free microtubes and were quickly placed into the liquid nitrogen and then stored in a $-80{ }^{\circ} \mathrm{C}$ freezer. The other ovary, the remaining implant, and the uterine horn were preserved into RNase DNase-free micro tubes pre-filled with a $10 \%$ formalin solution.

Steps in Histology Assessment

1. Tissue specimens were stained using hematoxylin and eosin (H\&E) and Masson's trichrome (Basic steps in histology provided in Table 1).

2. Using the IX71 OLYMPUS fluorescent microscope, the lamellas were observed with the aid of a pathologist and their data included the number of graph follicles, the number of corpus luteum, and atretic follicles in the ovaries, and the position of the implants was recorded according to the classification.

3. A pathologist who was blinded to the groups assessed the samples.

4. Histologically, the implants were scored based on a semi-quantitative assessment as follows (19-21).
0: No epithelium;

1: Extremely little (insufficient) to remain in the epithelial layers;

2: Maintaining the average epithelial layer with leukocyte infiltration;

3: The epithelial layers are well maintained and remain.

5. Masson's trichrome staining evaluated the presence of stroke and fibrous elements:

0 : No fibrosis;

1: Minimal growth of fibrous tissue;

2: Irregular fibrous tissue growth;

3: Integrated and hyalinized accumulated fibrosis.

Gene Expression Analysis

The real-time polymerase chain reaction (PCR) analysis is an essential method for gene expression in many biological research fields.

The stages of gene expression analysis using the realtime PCR analysis is based on 7 steps such as experimental sample collection, RNA extraction from the samples, the assessment of quantitative and qualitative RNA extraction, cDNA synthesis, primer design, the real-time PCR administration for measuring the expression level of the genes, and data analysis.

\section{Extracted RNA}

Total RNA will be extracted using the BIOTECH CORP CO.LTD kit (FAVORGEN, Japan) according to the manufacturer's instructions (Box 1).

\section{Quantitative and Qualitative RNA Extraction}

\section{A. Quality Study of Extracted RNA}

The extracted RNA samples will be checked for integrity and the purity level with spectrophotometry (Synergy HTX Multi-Mode Microplate Reader). Optical density (OD) at $260 \mathrm{~nm}$ shows the quantity of the RNA sample and the ratio of $260 / 280$ represents the quality of the RNA sample.

Absorption ratios: The purity of the RNA of each sample will be determined by calculating the 260/280 and 260/230 ratios. Ratios $260 / 280$ below 1.8 and $260 / 230$ below $1.8-2$ indicate protein contamination and organic compound contamination, respectively (22).

Electrophoresis on the agarose gel: RNA quality and integrity will be measured by the agarose gel electrophoresis method. The $28 \mathrm{~S}$ rRNA band to the $18 \mathrm{~S}$ rRNA band will be compared, if the $28 \mathrm{~S}$ band will be approximately twice the intensity of the $18 \mathrm{~S}$ band that will be generally represented good quality RNA.

\section{B. Quantitative RNA Extraction}

In this method, total RNA ( $\mu \mathrm{g}$ ) will be determined by the following formula.

Total RNA $(\mu \mathrm{g})=($ A 260$)(40 \mu \mathrm{g})(100)(0.05 \mathrm{~mL})$

Concentration $=$ Total $\mu \mathrm{g} / 50 \mu \mathrm{L}=\mu \mathrm{g} / \mu \mathrm{L}$ or $\mathrm{mg} / \mathrm{mL}$ (23) 
Table 1. Basic Steps in Histology

\begin{tabular}{|c|c|}
\hline Tissue Collection & $\begin{array}{l}\text { Placing the tissues of the uterine horn, implant, and ovary into the fixative container (formalin } 10 \% \text { ) immediately after } \\
\text { collection. }\end{array}$ \\
\hline Fixation & We used a $20: 1$ ratio of formalin $10 \%$ to tissue. \\
\hline Processing & $\begin{array}{l}\text { Tissue processing includes dehydration and clearing. } \\
\text { Dehydrating the tissues gently by immersion in increasing the concentrations of the alcohol ( } 70 \% \text { ethanol, } 1 \text { hour; First, } \\
80 \% \text { ethanol, second, } 80 \% \text { ethanol, } 1 \text { hour; First } 95 \% \text { ethanol, } 1 \text { hour; Second, } 95 \% \text { ethanol, } 1 \text { hour; First, absolute } \\
\text { ethanol, } 1.5 \text { hours; Second, absolute ethanol, } 1.5 \text { hours; Clearing: First, Xylene, } 1 \text { hour; Second, Xylene, } 1 \text { hour). }\end{array}$ \\
\hline $\begin{array}{l}\text { Infiltration with } \\
\text { paraffin wax }\end{array}$ & $\begin{array}{l}\text { Placing the tissues into the melted paraffin container in an incubator set at } 58^{\circ} \mathrm{C} \text { for } 1 \text { hour, repeated before the step } \\
\text { using freshly melted paraffin for } 1 \text { hour. This process of paraffin infiltration is a necessary step to harden the tissues } \\
\text { before their embedding. }\end{array}$ \\
\hline Embedding & $\begin{array}{l}\text { Placing tissue samples carefully positioned inside a metal base mold. The mold was filled with melted paraffin and } \\
\text { then immediately put on a cooling surface. }\end{array}$ \\
\hline Sectioning & $\begin{array}{l}\text { Sectioning the paraffin blocks was done using a microtome (Microtech cut } 4060 \text {, Germany) that cuts very thin (four } \\
\text { microns) sections of the paraffin-embedded tissues, and then they were floated on warm water and picked out on the } \\
\text { slides. }\end{array}$ \\
\hline Deparaffinization & Dewaxing the paraffin sections in xylene $2 \times 5$ minutes each. \\
\hline Rehydration & $\begin{array}{l}\text { Rehydrating in } 100 \% \text { ethanol } 2 \times 5 \text { minutes each, rehydrating in } 95 \% \text { ethanol } 2 \times 5 \text { minutes each, and then washing it } \\
\text { in the running tap water for } 3 \text { minutes. }\end{array}$ \\
\hline Staining & $\begin{array}{l}\text { H\&E: } \\
\text { Staining for } 10 \text { minutes in Harris hematoxylin, washing in the running tap water for } 3 \text { minutes and decolorizing briefly } \\
\text { in acid alcohol for } 2 \text { seconds. Next, wash and blue the sections in the running tap water for } 3 \text { minutes, followed by } \\
\text { staining it for } 2-5 \text { minutes in } 0.1 \% \text { aqueous eosin. Then, rinse it in the tap water for } 30 \text { seconds, dehydrate it in } 95 \% \\
\text { ethanol two times for } 2 \text { minutes each. In addition, dehydrate it in } 100 \% \text { ethanol two times for } 2 \text { minutes each and } \\
\text { clear the sections in a clearing agent two times for } 2 \text { minutes each. } \\
\text { Trichrome (Masson's stain): } \\
\text { 1. Deparaffinizing and hydrating the slides to distilled water; } \\
\text { 2. Applying } 250 \mu \mathrm{L} \text { of Bouins solution and allowing it to stand for } 30 \text { minutes; } \\
\text { 3. Rinsing the running tap water for } 5-10 \text { minutes to remove the yellow color; } \\
\text { 4. Using } 250 \mu \mathrm{L} \text { of Weigert's working solution for staining for } 10 \text { minutes and rinsing the tap water for } 10 \text { minutes; } \\
\text { 5. Utilizing } 250 \mu \mathrm{L} \text { Biebrich scarlet-acid fuchsin solution for } 10-15 \text { minutes and then washing it in distilled water; } \\
\text { 6. Using } 250 \mu \mathrm{L} \text { phosphomolybdic tungstic acid solution for } 10 \text { minutes or until the collagen is not red; } \\
\text { 7. Transferring the sections directly to the aniline blue solution and staining them for } 5-10 \text { minutes, followed by rinsing } \\
\text { them briefly in distilled water and differentiating; } \\
\text { 8. Using } 250 \mu \mathrm{L} \text { acetic acid solution for } 5 \text { minutes and then washing it in distilled water. } \\
\text { 9. Dehydrating the Sections very quickly through } 95 \% \text { ethyl alcohol, absolute ethyl alcohol, and clear in xylene. }\end{array}$ \\
\hline Cover slipping & $\begin{array}{l}\text { Placing two or three drops of the mounting medium (Entellan, Merck, Germany) onto the coverslip on the slide and } \\
\text { avoiding the formation of bubbles. }\end{array}$ \\
\hline
\end{tabular}

\section{cDNA Synthesis}

For all of the extracted RNA of the samples, RNA will be converted into complementary DNA (cDNA) with the prime script RT Reagent Kit Fast (Takara, Japan) according to the manufacturer's protocol. The following reaction mixture will be prepared on the ice and under a fume hood. In a final reaction, a volume of $30 \mu \mathrm{L}$ containing (24):

1. $5 \times$ PrimeScript $^{\mathrm{TM}}$ buffer (for Real-time), $6 \mu \mathrm{L}$

2. PrimeScript ${ }^{\mathrm{TM}} \mathrm{RT}$ enzyme mix I, $1.5 \mu \mathrm{L}$

3. Oligo dT primer, $1.5 \mu \mathrm{L}$

4. Random 6 mers, $1.5 \mu \mathrm{L}$

5. Total RNA, $3 \mu \mathrm{g}(1000 / \mathrm{OD} \times 3)$

6. RNase free $\mathrm{dH} 2 \mathrm{O}$, remaining volume up to $30 \lambda$.

The reaction mixture will be incubated under the subsequent conditions:

1. $37^{\circ} \mathrm{C}, 5$ minutes (Reverse transcription);

2. $85^{\circ} \mathrm{C}, 5$ seconds (Reverse transcriptase inactivation with heat treatment);

\section{3. $4{ }^{\circ} \mathrm{C}$ then cDNA will be stored at $-20^{\circ} \mathrm{C}$.}

\section{Primer Design}

The real-time PCR analysis will be performed in endometriotic lesions, uterine tissues, and peritoneal liquid. In addition, PRIMERBLAST and OLIGO7 software were used to design primer sequences (www.ncbi.nlm. nih.gov/tools/primer-blast).

\section{Real-Time PCR}

For real-time PCR analysis for miRNAs expression, the VEGFa, SRC-1, MCP-1, GPx-1, IL-6, IL-1 $\beta$, and endogenous control beta-actin primers (Table 2) were purchased from Biotech Company, Korea.

All reaction volumes will be $15 \mu \mathrm{L}$ containing:

a. A 2.5-fold diluted reverse-transcribed sample (cDNA), $2 \mu \mathrm{L}$

b. Syber (PrimeScript ${ }^{\mathrm{TM}}$ RT Master Mix (Perfect Realtime), Cat. \#RR036A, Takara, Japan), $7.3 \mu \mathrm{L}$; 


\section{Box 1. Isolation of Total RNA From Animal Tissues}

1. In general, $30 \mathrm{mg}$ of the tissue sample stored at the $-80{ }^{\circ} \mathrm{C}$ freezer was discarded and then the sample was grinded in liquid nitrogen to a fine powder with a mortar inside the sterilized foil and the powder was transferred to a new microcentrifuge tube.

2. In addition, $350 \mu \mathrm{L}$ of FARB buffer and $3.5 \mu \mathrm{L}$ of ß-mercaptoethanol was added and the sample was homogenized by using a rotor-stator homogenizer (micro/ spin, fudge/vortex QIAGEN Company, Itd, Iran).

3. A filter column will be placed in a collection tube and the sample mixture was transferred to the filter column. Then, it was centrifuged at full speed ( 18,000 x g) for 2 minutes.

4. The clarified supernatant from the collection tube was transferred to a new microcentrifuge tube, followed by measuring the volume of the supernatant.

5. One volume of $70 \%$ RNase-free ethanol was added and mixed well by vortexing

6. A FARB Mini Column was placed in a collection tube and the ethanol added sample mixture (including any precipitate) was transferred to the FARB Mini Column. Then, it was centrifuged at full speed for 1 minute. Further, the flow-through was discarded and the FARB Mini Column was returned to the collection tube.

7. Furthermore, $500 \mu \mathrm{L}$ of wash buffer 1 was added to the FARB Mini Column, and centrifuged at full speed for 1 minute. The flow-through was discarded and the FARB Mini Column was returned to the collection tube.

8. Moreover, $750 \mu \mathrm{L}$ of wash buffer 2 was added to the FARB Mini Column, then it was centrifuged at full speed for 1 minute, followed by discarding the flow-through and returning the FARB Mini Column to the collection tube.

9. The step was repeated for one more washing.

10. The FARB mini column was centrifuged at full speed for an additional 3 minutes to dry the FARB mini column.

11. The FARB mini column was placed on an elution tube

12. Finally, $40 \mu \mathrm{L}$ of $\mathrm{RNase}$-free $\mathrm{ddH} 2 \mathrm{O}$ was added to the membrane center of the FARB mini column and the FARB mini column was stood for 1 minute.

13. RNA was stored at $-70^{\circ} \mathrm{C}$.

Note: It should be noted that all the stages of RNA extraction were performed in sterile conditions on the ice and under the hood

Note: Extract RNA from the peritoneal fluid: After the peritoneal liquid on the ice, centrifugation at the speed of $\sim 8000 \times \mathrm{g}$ for 5 minutes at $4{ }^{\circ} \mathrm{C}$. Then, remove all the supernatant and add 350 $\mu \mathrm{L}$ of FARB buffer and $3.5 \mu \mathrm{L}$ of $ß$-mercaptoethanol to the cell pellet. Vortex vigorously for 1 minute to resuspend the cells completely and follow the other steps in the extraction of RNA from the tissue.

c. The $0.6 \mu \mathrm{L}$ of each forward and reverse primer;

d. $\mathrm{H} 2 \mathrm{O}$ (satirized distilled water), $4.5 \mu \mathrm{L}$;

e. All reactions will be run in duplicate.

The real-time PCR will be executed on the Corbett RotorGene 6000 software (Rotor-Gene 6000 Version 1.7, Australia).

The run will be executed as a 2-stepped protocol as follows.

1. Initialization Step: 5 minutes $95^{\circ} \mathrm{C}$ pursued by 40 rounds of:
2. Denaturation Step: 20 seconds at $95{ }^{\circ} \mathrm{C}$;

3. Annealing Step: 30 seconds at $61^{\circ} \mathrm{C}$;

4. Extension/elongation Step: 8 seconds at $72{ }^{\circ} \mathrm{C}$.

Calculated Gene Expression and Data Analysis

The delta-delta $\mathrm{Ct}$ formula will be used to calculate the gene expression (25).

a. $\Delta \mathrm{Ct}=\mathrm{Ct}$ (gene of interest) $-\mathrm{Ct}$ (endogenous control gene)

b. $\Delta \Delta \mathrm{Ct}=\Delta \mathrm{Ct}$ (Sample) $-\Delta \mathrm{Ct}$ (Control average)

c. Fold gene expression $=2^{-(\Delta \Delta \mathrm{Ct})}$

\section{Sample Size}

In this study, the sample size was calculated considering the type 1 error of $5 \%$, the power of $80 \%$, the standard error of 5.2 , the effect size of 7.7 , and the attrition of $10 \%$. As a result, 8 mice in each of the 4 subgroups were required for the first phase.

In the second and third stages of this study, the number of samples was calculated based on the standard error of 8.9, followed by determining 7 samples per group given the effect size of 19.2 and the attrition of $10 \%$.

Statistical Analysis

The Stata (version 13) and GraphPad Prism software (version 8) will be used for the statistical analysis and generate graphs. Continuous variables will be checked for normality using the Shapiro-Wilk test, the measure of dispersion and central tendency, and histogram graph.

The obtained results will be expressed as means and standard deviations and the difference effect size (i.e., mean difference, standardized mean difference, and mean ratio). The mean volume and scores of the extent and adhesion of the endometriotic lesions, as well as angiogenic, inflammatory, and stress oxidative gene expression levels and fecundity status will be compared between the groups.

The metric variables will be compared by $t$ test, one-way ANOVA test, and Bonferroni post hoc tests. Further, the non-metric variables will be examined by the KruskalWallis and Mann-Whitney U tests.

In the same group, metric (preceding and subsequent to the medical treatment) and non-metric variables will be evaluated by repeated-measures ANOVA and the Generalized Estimating Equation Model, respectively. $P$ values of $<0.05$ will be taken into account as statistically significant.

\section{Results}

This experimental study began in April 2017 and will be finished in 2020.

\section{Discussion}

In this study, we will introduce the optimum approaches for the induction of endometriosis in terms of histologic, 
Table 2. Oligonucleotide Primer Sequences

\begin{tabular}{|c|c|c|c|c|}
\hline Primer & & $s\left(5^{\prime}-3^{\prime}\right)$ & Length ( $\mathrm{n})$ & $\operatorname{Tm}\left({ }^{\circ} \mathrm{C}\right)$ \\
\hline \multirow{2}{*}{ Beta-actin } & Forward & CTTCGTTGCCGGTCCACAC & 19 & 61.7 \\
\hline & Reverse & TACAGCCCGGGGAGCATC & 18 & 60.7 \\
\hline \multirow{2}{*}{ VEGF $\alpha$} & Forward & CAGATCATGCGGATCAAACCTC & 22 & 62.1 \\
\hline & Reverse & TCTTTCTTTGGTCTGCATTCAC & 22 & 58.4 \\
\hline \multirow{2}{*}{ SRC-1 } & Forward & GATGGGCCAGATGCAAATGAG & 21 & 61.3 \\
\hline & Reverse & AGAAGGTCAGTGGACGAGAG & 20 & 60.5 \\
\hline \multirow{2}{*}{ MCP-1 } & Forward & AGCACCAGCCAACTCTCAC & 19 & 59.5 \\
\hline & Reverse & CTTGTAGCTCTCCAGCCTACTC & 22 & 64 \\
\hline \multirow{2}{*}{ GPx-1 } & Forward & CACCAGGAGAATGGCAAGAATG & 22 & 62.1 \\
\hline & Reverse & GGAAGGTAAAGAGCGGGTGAG & 21 & 63.3 \\
\hline \multirow{2}{*}{ IL-6 } & Forward & CTGCAAGAGACTTCCATCCAG & 21 & 59.8 \\
\hline & Reverse & AGTGGTATAGACAGGTCTGTTGG & 23 & 60.6 \\
\hline \multirow{2}{*}{ IL-1 $\beta$} & Forward & GAAATGCCACCTTTTGACAGTG & 22 & 58.4 \\
\hline & Reverse & TGGATGCTCTCATCAGGACAG & 21 & 59.8 \\
\hline
\end{tabular}

immunologic, and fertility characteristics using the 2 most common approaches (i.e., peritoneal and ovarian). These mice models of endometriosis will enable a noninvasive diagnostic approach for a better understanding of the pathophysiology of endometriosis and possibly improves the treatment modalities, as observed in other studies (26).

This selected model will evaluate the fecundity and gene expression of inflammatory and angiogenesis factors in comparison with sham and control groups in the first generation. This allows us to find out about the possible permanent epigenetic changes in the subsequent generation. Some studies showed that, in the first generation of endometriosis, it has a negative effect on oocyte quality and embryo development (19).

Studies further demonstrated that the presence of inflammatory, angiogenesis, and oxidative stress factors play an essential role in the generation and maintenance of endometriotic lesions (26). The present study will analyze the expression of these factors in the lesions of endometriosis in order to evaluate their involvement in endometriosis establishment and growth.

Moreover, it was aimed to investigate the effectiveness of vitamin $\mathrm{C}$ on the improvement of endometriosis implants. Vitamin $\mathrm{C}$ is an antioxidant with anti-inflammatory and anti-angiogenesis effects and can be used to prevent invasion and metastasis. Thus, the reduction of the weight and volume of implants caused by vitamin $C$ could be the outcome of the cell cycle arrest, altering the tissue edema with consequent tissue atrophy, reduced cell proliferation, and apoptosis induction $(8,27)$.

A limitation of this study was the creation of one treatment group and one control group in the third study phase. It was better to compare the antioxidant treatment with the standard treatment, which is a proven therapy for humans. However, it was impossible due to the scope of the study. In this study, only the gene expressions of VEFG, MCP-1, SRC-1, IL-1 $\beta$, IL-6, and GPX will be evaluated while not assessing the other cytokines, because the tissue samples are insufficient for their evaluation.

Therefore, further studies are recommended that aim to prevent the disease in the next generation of experimental groups and compare different antioxidant treatments with several doses in the endometriosis induction model.

\section{Conflict of Interests}

Authors declare that they have no conflict of interests.

\section{Ethical Issues}

The protocol of the study was approved by the Ethics Committee of Shahid Beheshti University of Medical Sciences, Tehran, Iran (ethics code IR.SBMU. PHNM.1395.688). All animals were performed in accordance with the Animals (Scientific Procedures) Act 1986 Amendment Regulations 2012. The checklist for working with laboratory animals was completed on the basis of the "Guidelines for Working with Laboratory Animals of the Ministry of Health and Medical Education of Iran" and was submitted along with the proposal. All procedures will be conducted at the Cellular-Molecular Research Center of Kurdistan University of Medical Sciences.

\section{Financial Support}

This manuscript, a part of a Ph.D. thesis submitted by Hayedeh Hoorsan, was funded by the Research Deputy of Shahid Beheshti University of Medical Science, Tehran, Iran.

\section{Acknowledgments}

The authors wish to thank the members of Cellular and Molecular Research Center, Kurdistan University of Medical Sciences (Dr. Zareie, Dr. Hassanzadeh, Ms. P. Khalvatian, Ms. F. Zamani, and Mr. J. Hossaini) and the Reproductive Endocrinology Research Center Staff (Ms. M. Noroozzadeh) for their continued support during the study. 


\section{References}

1. Cureton BL. A Critical Review of Endometriosis Pathology. Ann Arbor: University of South Carolina; 2013.

2. Taylor HS, Pal L, Sell E. Speroff's Clinical Gynecologic Endocrinology and Infertility. Wolters Kluwer Lippincott Williams \& Wilkins; 2019.

3. Zhang H, Niu Y, Feng J, Guo H, Ye X, Cui H. Use of proteomic analysis of endometriosis to identify different protein expression in patients with endometriosis versus normal controls. Fertil Steril. 2006;86(2):274-282. doi:10.1016/j.fertnstert.2006.01.028

4. Berek JS. Berek \& Novak's Gynecology. 16th ed: Wolters Kluwer; 2019.

5. von Theobald P, Cottenet J, Iacobelli S, Quantin C. Epidemiology of endometriosis in France: a large, nationwide study based on hospital discharge data. Biomed Res Int. 2016;2016:3260952. doi:10.1155/2016/3260952

6. Arosh JA, Lee J, Balasubbramanian D, et al. Molecular and preclinical basis to inhibit PGE2 receptors EP2 and EP4 as a novel nonsteroidal therapy for endometriosis. Proc Natl Acad Sci U S A. 2015;112(31):9716-9721. doi:10.1073/ pnas. 1507931112

7. Chapron C, Marcellin L, Borghese B, Santulli P. Rethinking mechanisms, diagnosis and management of endometriosis. Nat Rev Endocrinol. 2019;15(11):666-682. doi:10.1038/ s41574-019-0245-Z

8. Erten OU, Ensari TA, Dilbaz B, et al. Vitamin C is effective for the prevention and regression of endometriotic implants in an experimentally induced rat model of endometriosis. Taiwan J Obstet Gynecol. 2016;55(2):251257. doi:10.1016/j.tjog.2015.07.004

9. Giudice LC, Evers JLH, Healy DH. Endometriosis: Science and Practice. 1st ed. New York, NY: Wiley-Blackwell; 2012.

10. Santanam N, Kavtaradze N, Murphy A, Dominguez C, Parthasarathy S. Antioxidant supplementation reduces endometriosis-related pelvic pain in humans. Transl Res. 2013;161(3):189-195. doi:10.1016/j.trsl.2012.05.001

11. Gupta S, Harlev A, Agarwal A. Endometriosis: A Comprehensive Update. Cham: Springer; 2015.

12. Ilie I, Ilie R. Cytokines and endometriosis--the role of immunological alterations. Biotechnology, Molecular Biology and Nanomedicine. 2013;1(2):8-19.

13. 13. Hoffman BL, Schorge JO, Bradshaw KD, Halvorson LM, Schaffer JI, Corton MM. Williams Gynecology. 3rd ed. New York: McGraw-Hill Education; 2016.

14. Capobianco A, Rovere-Querini P. Endometriosis, a disease of the macrophage. Front Immunol. 2013;4:9. doi:10.3389/ fimmu.2013.00009

15. Animals Scientific Procedures Act. Available from: https:// assets.publishing.service.gov.uk/government/uploads/ system/uploads/attachment_data/file/535574/workingwith-wild-animals-160706.pdf. Published July 2016.

16. Azimirad A, Alborzi S, Kumar PV, Zarei A, Azimirad M. The effects of levamisole on experimental endometriosis: a randomized controlled trial in a rat model. Arch Gynecol Obstet. 2013;288(6):1301-1308. doi:10.1007/s00404-0132895-8

17. Sykes AV, Baptista FD, Gonçalves RA, Andrade JP. Directive 2010/63/EU on animal welfare: a review on the existing scientific knowledge and implications in cephalopod aquaculture research. Rev Aquac. 2012;4(3):142-162. doi:10.1111/j.1753-5131.2012.01070.x

18. Soysal D, Kızıldağ S, Saatlı B, et al. A novel angiogenesis inhibitor bevacizumab induces apoptosis in the rat endometriosis model. Balkan J Med Genet. 2014;17(2):7380. doi:10.2478/bjmg-2014-0077

19. Gerstein AS. Molecular Biology Problem Solver: A Laboratory Guide. New York, NY: John Wiley \& Sons; 2004.

20. Kiani K, Movahedin M, Malekafzali $\mathrm{H}$, et al. Effect of the estrus cycle stage on the establishment of murine endometriosis lesions. Int J Reprod Biomed (Yazd). 2018;16(5):305-314.

21. Wimmer I, Tröscher AR, Brunner F, et al. Systematic evaluation of RNA quality, microarray data reliability and pathway analysis in fresh, fresh frozen and formalin-fixed paraffin-embedded tissue samples. Sci Rep. 2018;8(1):6351. doi:10.1038/s41598-018-24781-6

22. Cirera S. Highly efficient method for isolation of total RNA from adipose tissue. BMC Res Notes. 2013;6:472. doi:10.1186/1756-0500-6-472

23. Farrell RE Jr. RNA Methodologies: Laboratory Guide for Isolation and Characterization. 5th ed. USA: Academic Press; 2017.

24. TaKaRa . TaKaRa’s Perfect Real Time PCR Product Guide. https://www.ozyme.fr/gammes/tak/pdf/pcrq-guideproduits.pdf.

25. Karlen Y, McNair A, Perseguers S, Mazza C, Mermod N. Statistical significance of quantitative PCR. BMC Bioinformatics. 2007;8(1):131. doi:10.1186/1471-2105-8131

26. Machado DE, Berardo PT, Palmero CY, Nasciutti LE. Higher expression of vascular endothelial growth factor (VEGF) and its receptor VEGFR-2 (Flk-1) and metalloproteinase-9 (MMP-9) in a rat model of peritoneal endometriosis is similar to cancer diseases. J Exp Clin Cancer Res. 2010;29:4. doi:10.1186/1756-9966-29-4

27. Durak Y, Kokcu A, Kefeli M, Bildircin D, Çelik H, Alper T. Effect of vitamin $\mathrm{C}$ on the growth of experimentally induced endometriotic cysts. J Obstet Gynaecol Res. 2013;39(7):1253-1258. doi:10.1111/jog. 12050

(c) 2020 The Author(s); This is an open-access article distributed under the terms of the Creative Commons Attribution License (http:// creativecommons.org/licenses/by/4.0), which permits unrestricted use, distribution, and reproduction in any medium, provided the original work is properly cited. 